\title{
Laparoscopic Hysterectomy in a Patient with Ventriculo- Peritoneal Shunt after Multiple Cesarean Sections
}

\author{
Islam H Metwally, PhD, MRCS ${ }^{*}$, Mohamed Yousri ${ }^{1}$, Dina M Elsaeed, MSc ${ }^{2}$ and Amani \\ Tarbay, $\mathrm{MSc}^{3}$
}

${ }^{1}$ Department of Surgical Oncology, Oncology Center Mansoura University (OCMU), Egypt

${ }^{2}$ Department of Obstetrics and Gynecology, Mansoura University Hospitals (MUH), Mansoura University, Egypt

${ }^{3}$ Department of Anesthesia, Mansoura University Hospitals (MUH), Egypt

\begin{abstract}
Patients with ventriculo-peritoneal shunt (VPS) for hydrocephalus had an improved survival and are more encountered in need of abdominal surgery. Laparoscopic surgery has been reported safe for these patients, although infrequently. At least 3 types of complications had been recorded: shunt obstruction, infection, and vaginal migration. We report a case of middle-aged female with endometrial hyperplasia and VPS who has done laparoscopic hysterectomy safely. The authors encourage laparoscopic surgery in this subset of patients when indicated with some precautions, including minimal insufflation pressure, $\mathrm{CO} 2$ monitoring, minimal Trendelenburg, and vaginal stump closure.
\end{abstract}

Keywords

Endometrial hyperplasia, Hydrocephalus intracranial pressure, Ventriculoperitoneal shunts, Minimally invasive hysterectomy

\section{Introduction}

Endometrial hyperplasia with atypia is a precursor lesion for endometrioid type endometrial cancer [1], and there has been an increasing trend toward laparoscopic hysterectomy for endometrial pathology.

Thanks to the advance in neurosurgery, patients with ventriculoperitoneal shunt (VPS) as a part of the treatment of hydrocephalus, either congenital or acquired causes have a longer survival and thus are at increasing risk of developing abdominal pathology necessitating surgery [2].

Herein, we discuss a patient with VPS with atypical endometrial hyperplasia treated by laparoscopic hysterectomy.

\section{Case Presentation}

Female patient aged 43-years-old with 4 offsprings with body mass index $31.2 \mathrm{~kg} / \mathrm{m}^{2}$ came to the hospital complaining of abnormal uterine bleeding, dilatation and curettage done revealed atypical complex endometrial hyperplasia. Patient had a history of multiple cesarean sections with evident Pfannenstiel scar healed by primary intention. In addition, the patient developed an acquired hydrocephalus 3 years ago for which a VPS was inserted. Also, she had a history of oral contraception followed by intrauterine device insertion, which was missed intrauterine and was removed transvaginally two and half months ago.

The patient had normal bloods and vital signs. Computed tomography of the brain on admission was normal and neurosurgical consultation answered that there is no current contraindication for surgery. Magnetic resonance imaging (MRI) of the pelvis showed endometrial plate thickness $8 \mathrm{~mm}$, right adnexal simple cyst $2 \mathrm{~cm}$ and multiple uterine fibroids (submucous, intramural and subserous) largest $2 \times$ $1.7 \mathrm{~cm}$ (Figure 1). Conventional elective total laparoscopic hysterectomy with preservation of the right ovary was done using Ligasure $5 \mathrm{~mm}$ (Figure 2). The insufflation pressure was kept between $12 \mathrm{mmHg}$ and $14 \mathrm{mmHg}$, and the patient was put in lithotomy position with mild Trendelenburg. The shunt was recognized at the beginning of the surgery (Figure 2).

*Corresponding author: Islam H Metwally, PhD, MRCS, Department of Surgical Oncology, Oncology Center Mansoura University (OCMU), Geehan Street, Dakahlia Governorate, Postal code 35516, Egypt

Accepted: September 18, 2021

Published online: September 20, 2021

Citation: Metwally IH, Yousri M, Elsaeed DM, et al. (2021) Laparoscopic Hysterectomy in a Patient with VentriculoPeritoneal Shunt after Multiple Cesarean Sections. Ann Minim Invasive Surg 3(1):31-34 


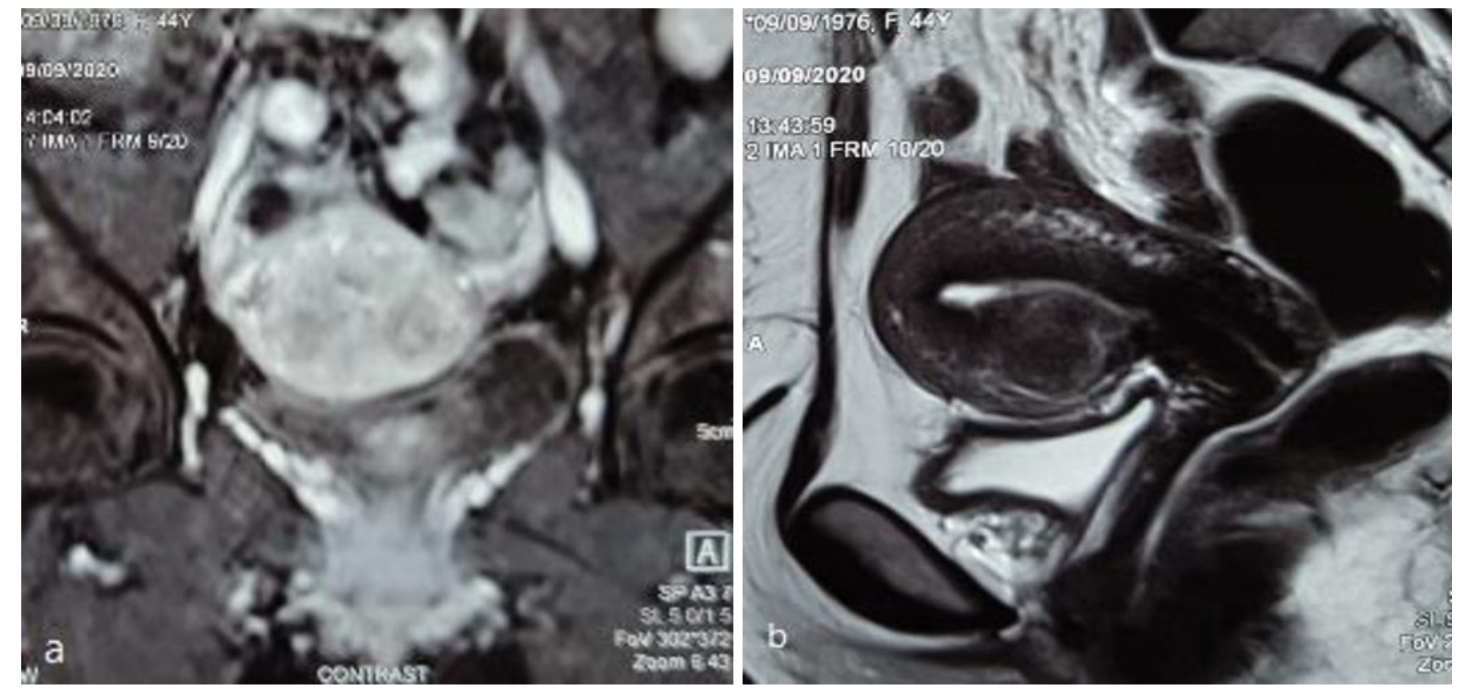

Figure 1: MRI showing bulky uterus with multiple fibroid and endometrial plate thickening (a) Transverse view; (b) Sagittal view.
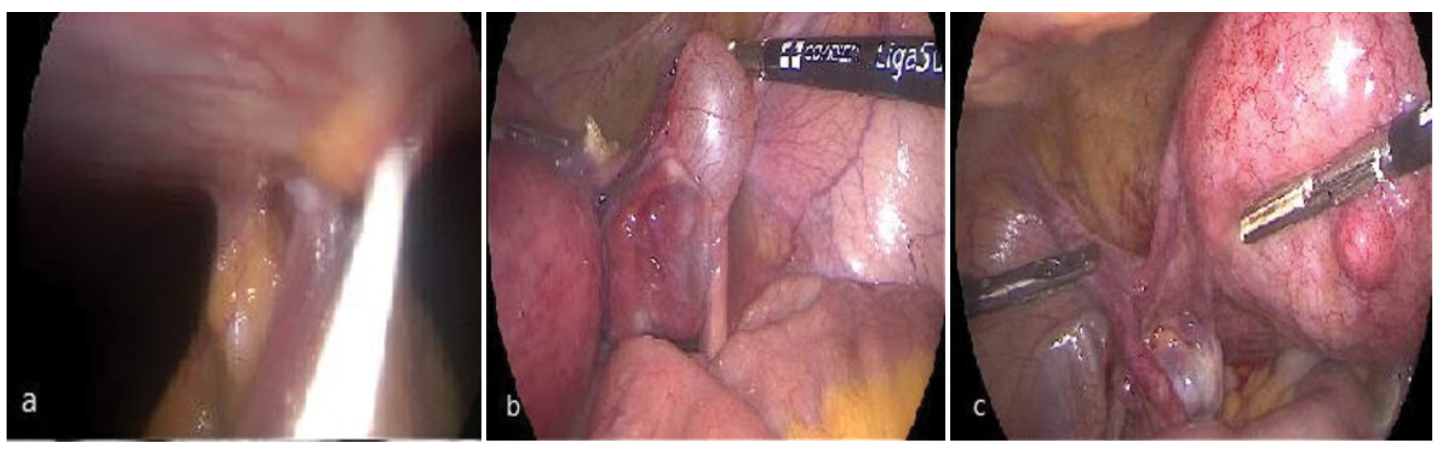

Figure 2: Laparoscopic view of (a) The shunt at the anterior abdominal wall; (b) The right ovarian cyst after ligation of round ligament; (c) Bulky uterus with multiple fibroids.

Adhesions were noticed between the bladder and the uterus probably from the previous cesarean sections. At the end of the surgery intracorporeal suturing of the vaginal stump, followed by transverse rectus abdominis (TAB) block was done. The patient was discharged the day after with smooth postoperative course and final pathology revealed simple endometrial hyperplasia with adenomyosis and leiomyoma and right para tubal simple cyst. Intracranial pressure (ICP) was not measured, however; there was no complaint or headache noticed by the patient after the surgery.

\section{Discussion}

VPS is the most commonly used procedure to treat hydrocephalus. The tubing is tunneled subcutaneously, with its distal end lying free in the peritoneal cavity.

Laparoscopic surgery in patients with VPS has been reported in cholecystectomy [3-7], salpingectomy [8], ileocecal resection [9], colectomy [2,10], gastrectomy [10], adrenal adenoma excision [11], stomas, cystoplasty, bladder neck reconstruction, testicular vessel clipping and fascial slinging [12].

Baskin, et al. recorded the first case of failure of VPS following laparoscopic procedure where the patient developed acute distal catheter obstruction. They concluded that laparoscopic surgery may represent a potential danger in patients with pre-existing cerebrospinal fluid (CSF) shunts [13]. In addition, infection was reported in 2 cases of laparoscopic cholecystectomy requiring shunt removal [7].

The risk of neurological injury in VPS patients during laparoscopy is derived from peritoneal insufflation and relates to two primary causes. The first is impaired CSF drainage due to a sustained elevated distal pressure gradient or an acute distal catheter obstruction. The second is the potential for retrograde insufflation of the CSF spaces through an incompetent shunt valve mechanism [13]. Other theoretical complications include infection and increased intracranial blood volume secondary to elevated venous pressure or hypercapnia. An acute increase in intracranial pressure may result in the dangerous combination of hypertension with bradycardia [12].

These possible complications led to various recommendations for managing patients with a VPS during minimally invasive surgery, such as: close observation, aggressive monitoring, and cerebrospinal fluid drainage [12]. Distal shunt catheter externalization performed during the surgery may be an option, especially in dirty abdominal 
Citation: Metwally IH, Yousri M, Elsaeed DM, et al. (2021) Laparoscopic Hysterectomy in a Patient with Ventriculo-Peritoneal Shunt after Multiple Cesarean Sections. Ann Minim Invasive Surg 3(1):31-34

operations. Internalization of the distal shunt catheter would then be performed after a liaison with a neurosurgeon, and some patients may need an alternative destination as ventriculo-atrial and ventriculo-pleural shunts [14].

Neale and Falk reported that the modern anti-reflux systems had not shown any retrograde flow when exposed to pressures as high as $350 \mathrm{mmHg}$ in an in-vitro experiments [15]. Thus, the clamping or externalization of the shunt catheter is probably unnecessary, and on the other hand, whether clamping of the shunt could actually exacerbate increases in ICP is not known [2]. Uzzo, et al. described the results of intraoperative intracranial pressure monitoring in 2 patients in whom intracranial pressure increased promptly at abdominal insufflation. However, they documented no intraoperative symptoms and no significant change in cerebral perfusion pressure, defined as mean arterial pressure minus intracranial pressure, or end tidal carbon dioxide associated with laparoscopy. In addition, plain X-ray of the skull confirmed that no gas traveled retrograde into the ventricles [16].

Laparoscopic hysterectomy in VPS patients was only reported twice by Houten, et al. [17] and by Davidson, et al. [18]. The first one was complicated by migration of the shunt through the open vaginal stump.

When the details of the type of VPS catheter are not available, it is very important to know when the VPS was inserted. Around 1960, the combined invention of artificial valves and silicone led to a worldwide therapeutic breakthrough. A VPS catheter with an anti-reflux valve has been marketed since the late seventies, and it has been used in most cases since then [19].

In our patient, although we did not do invasive monitoring of intracranial pressure, we kept the insufflations pressure between $12-14 \mathrm{mmHg}$, minimized the Trendelenburg position aiming to avoid hypercapnia, suture closed the vaginal stump to avoid VPS shunt migration.

\section{Conclusion}

Laparoscopic hysterectomy is safe in patients with VPS, thus the choice of open/minimally invasive surgery in these patients should follow the normal guidance with some precautions. The authors would recommend minimal working insufflation pressure, $\mathrm{CO}_{2}$ monitoring, minimal Trendelenburg, and suture closure of the vaginal stump.

\section{Conflict of Interest}

All authors declare no conflict of interest.

\section{Funding}

No funding was received.

\section{Ethical Approval}

All procedures performed in the study involving human participants were in accordance with the ethical standards of the institutional research committee and with the 1964 Helsinki declaration and its later amendments or comparable ethical standards.

\section{Informed Consent}

Informed consent was obtained from the patient included in the study.

\section{References}

1. Travaglino A, Raffone A, Saccone G, et al. (2019) Endometrial hyperplasia and the risk of coexistent cancer: WHO versus EIN criteria. Histopathology 74: 676-687.

2. Ichikawa Y, Matsuda C, Mizushima T, et al. (2019) Safety of laparoscopic colorectal surgery in patients with ventriculoperitoneal shunt. Asian J Endosc Surg 12: 264-268.

3. Damrah O, Naik P, Fusai G, et al. (2011) Is laparoscopic cholecystectomy safe for acute cholecystitis in the presence of ventriculo-peritoneal shunt? Int J Surg Case Rep 2: 157-158.

4. Cobianchi L, Dominioni T, Filisetti C, et al. (2014) Ventriculoperitoneal shunt and the need to remove a gallbladder: Time to definitely overcome the feeling that laparoscopic surgery is contraindicated. Ann Med Surg (Lond) 3: 65-67.

5. Yoshihar T, Tomimar Y, Noguchi K, et al. (2017) Feasibility of laparoscopic cholecystectomy in patients with cerebrospinal fluid shunt. Asian J Endosc Surg 10: 394-398.

6. Hammill CW, Au T, Wong LL (2010) Laparoscopic cholecystectomy in a patient with a ventriculoperitoneal shunt. Hawaii Med J 69: 103-104.

7. Allam E, Patel A, Lewis G, et al. (2011) Cholecystectomy in patients with prior ventriculoperitoneal shunts. Am J Surg 201: 503-507.

8. Sankpal R, Chandavarkar A, Chandavarkar M (2011) Safety of laparoscopy in ventriculoperitoneal shunt patients. J Gynecol Endosc Surg 2: 91-93.

9. Torigoe T, Koui S, Uehara T, et al. (2013) Laparoscopic cecal cancer resection in a patient with a ventriculoperitoneal shunt: A case report. Int J Surg Case Rep 4: 330-333.

10. Wadhwa S, Hanna GK, Barina AR, et al. (2012) Gastrointestinal cancer surgery in patients with a prior ventriculoperitoneal shunt: The department of veterans affairs experience. Gastrointest Cancer Res 5: 125-129.

11. Staikou C, Tsaroucha A, Mani A, et al. (2012) Transcranial doppler monitoring of middle cerebral flow velocity in a patient with a ventriculoperitoneal shunt undergoing laparoscopy. J Clin Monit Comput 26: 487-489.

12. Jackman SV, Weingart JD, Kinsman SL, et al. (2000) Laparoscopic surgery in patients with ventriculoperitoneal shunts: Safety and monitoring. J Urol 164: 1352-1354.

13. BaskinJJ,VishtehAG, WescheDE, etal.(1998)Ventriculoperitoneal shunt failure as a complication of laparoscopic surgery. JSLS 2: 177-180.

14. Goel A, Craven C, Matloob S, et al. (2019) CSF-diverting shunts: Implications for abdominal and pelvic surgeons; A review and pragmatic overview. Ann Med Surg (Lond) 48: 100-104.

15. Neale ML, Falk GL (1999) In vitro assessment of back pressure on ventriculoperitoneal shunt valves. Is laparoscopy safe? Surg Endosc 13: 512-515.

16. Uzzo RG, Bilsky M, Mininberg DT, et al. (1997) Laparoscopic surgery in children with ventriculoperitoneal shunts: Effect of pneumoperitoneum on intracranial pressure-preliminary experience. Urology 49: 753-757. 
Citation: Metwally IH, Yousri M, Elsaeed DM, et al. (2021) Laparoscopic Hysterectomy in a Patient with Ventriculo-Peritoneal Shunt after Multiple Cesarean Sections. Ann Minim Invasive Surg 3(1):31-34

17. Houten JK, Smith S, Schwartz AY (2017) Vaginal migration of ventriculoperitoneal shunt catheter and cerebrospinal fluid leak as a complication of hysterectomy. World Neurosurgery 104 : 1046.e13-1046.e14.

18. Davidson, Aung KLL (2018) Safety of Laparoscopic Pelvic Surgery in a Patient with a Ventriculoperitoneal Shunt. In AUSTRALIAN \& NEW ZEALAND JOURNAL OF OBSTETRICS \& GYNAECOLOGY.

19. Aschoff A, Kremer P, Hashemi B, et al. (1999) The scientific history of hydrocephalus and its treatment. Neurosurg Rev 22: 67-93.

DOI: $10.36959 / 351 / 588$ 